\title{
Maxentius 3D Project
}

\author{
LUCIA MARSICANO, SAVERIO GIULIO MALATESTA, FRANCESCO LELLA, \\ EMANUELA D’IGNAZIO, ELEONORA MASSACCI AND SIMONE ONOFRI \\ Sapienza University, Rome, Italy
}

\begin{abstract}
The aim of the project is to propose a full 3D model of the Circus of Maxentius in Rome encompassing all the aspects of the environment, as well as the architectural system. The circus is part of a complex built by Maxentius at the beginning of the IV century AD. The Maxentian complex is situated on the Via Appia between the second and the third mile; today this area is part of the Parco Regionale dell'Appia Antica, where the need to preserve the ecosystem makes it impossible to remove the vegetation. For this reason a large part of the circus is covered by the vegetation, making the survey of the entire structure impossible for researchers. The starting point was a study of the archaeological data, and then the team carried out a targeted field survey to integrate the published data with new information useful for creating a metrically correct reconstruction of the monument. To model both the landscape and the architectural structures, Blender, an open source software, was utilized, and to model the statues ZBrush, a proprietary software package, was used. Each element was modeled using scientific evidence or, lacking that, by employing analogies. The result is a metrically and scientifically correct 3D model of the Circus of Maxentius useful for studying the monument from a new point of view. By integrating archaeological data and using 3D graphics, it was possible to verify the hypothesis of reconstruction of the monument.
\end{abstract}

\section{Key words:}

Archaeology, 3D reconstruction, Blender, Zbrush.

\section{SDH Reference:}

Lucia Marsicano, et al., Maxentius 3D Project, 2017. SDH, 1, 2, 477-490.

DOI :10.14434/sdh.v1i2.23199

\section{INTRODUCTION}

The Maxentian complex, composed of the palace, the Mausoleum of Romulus and the Circus of Maxentius, is situated along the Via Appia between the second and the third milestones. The area is part of the Regional Park of the Appia Antica, comprised of 3500 hectares. The Park includes eleven miles of the Via Appia, the Caffarella valley (200 ha.), the archaeological area of the ancient Via Latina, the Aqueducts Park (240 ha.), the Tormarancia estate (220 ha.) and the Farnesina estate (180 ha.). The main purpose of the Park is to preserve the ecosystem, protecting its flora and fauna. For this reason, the structure of the circus is covered by dense vegetation, and it is not possible to see the monument in its entirety. The state of preservation of the circus, its historical importance and questions about

Author's address: Lucia Marsicano, Saverio Giulio Malatesta, Francesco lella: Archeo\&Arte 3D - DigiLab, Sapienza University, Rome, Italy; Emanuela d'Ignazio, Eleonora Massacci, Simone Onofri: Specialization School in Classical Archaeology, Sapienza University, Rome, Italy.

Permission to make digital or hardcopies of part or all of this work is granted without fee according to the open access policy of SDH.

(C) 2017 SDH Open Access Journal 
the arrangement of the monument are the reasons why our team decided to make a 3D model of the Circus of Maxentius (Fig. 1).

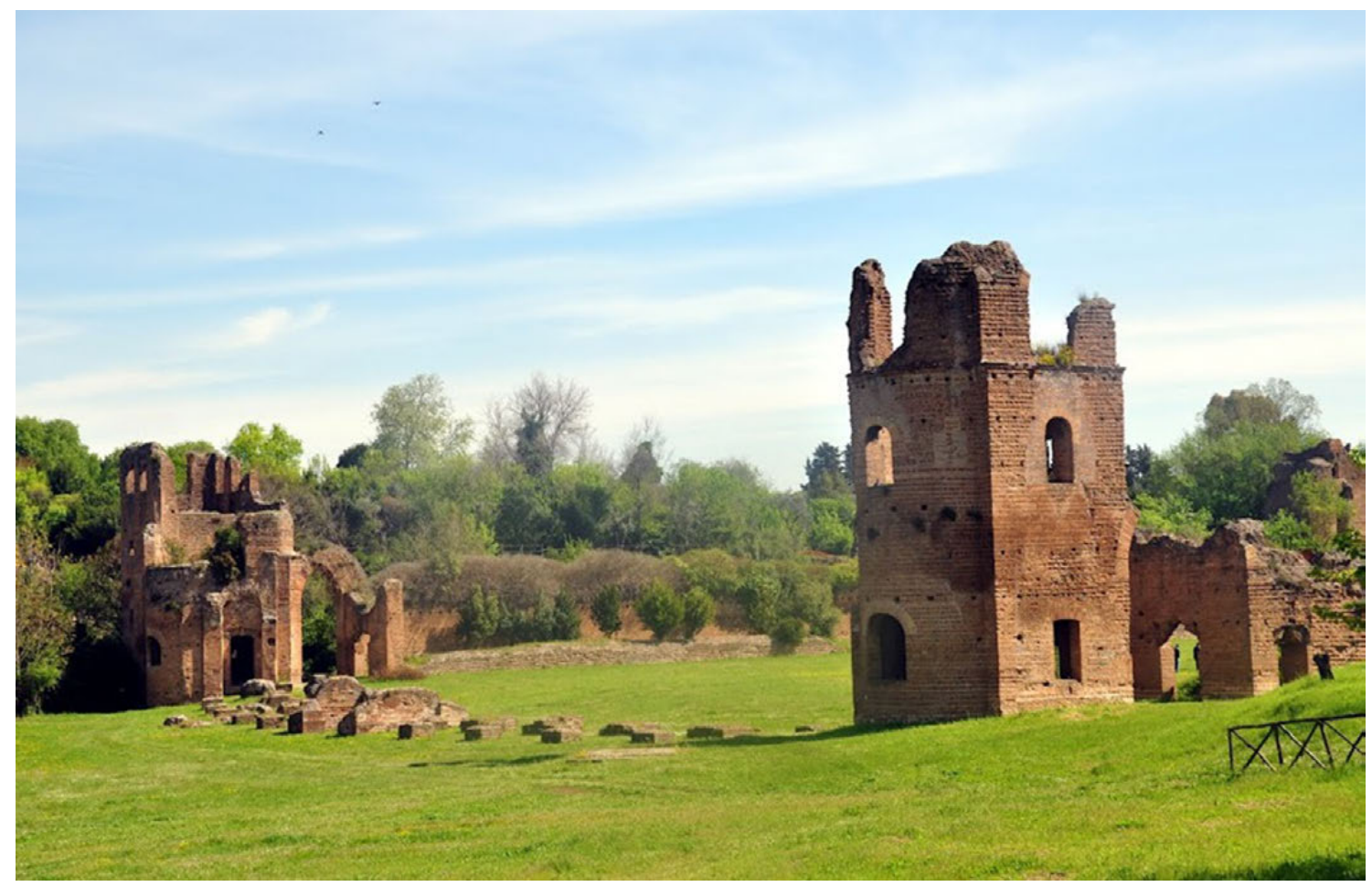

Figure 1. Circus of Maxentius

We began with the study of the archaeological data, especially cartography, axonometric drawings and plans. Then the team carried out a limited field survey to collect more data. Unfortunately, because the vegetation covers such a large part of the monument, it was not possible to significantly integrate the published data. While the plans and axonometric drawings were the starting point for gaining an understanding of the structural features of the monument, historical illustrations were also useful in proposing a likely reconstruction. Also useful were a large number of drawings which show the state of preservation of the monument during the past as well as a hypothetical reconstruction. To complete the 3D model of the circus, other details were included. It was possible to insert detailed elements, like the machine used to count the laps, and some statues, thanks to fragments found during the excavations [Luschi 1999]. Furthermore, there are several illustrations from the Roman period, such as mosaics and reliefs, which were useful for adding more details.

Once all the data had been collected that were useful for making an accurate reconstruction, the team went ahead with the 3D modeling using the open source software Blender. ZBrush, a proprietary software package that allows us to model detailed objects easily and quickly, was used to model the statues (Fig. 2). 


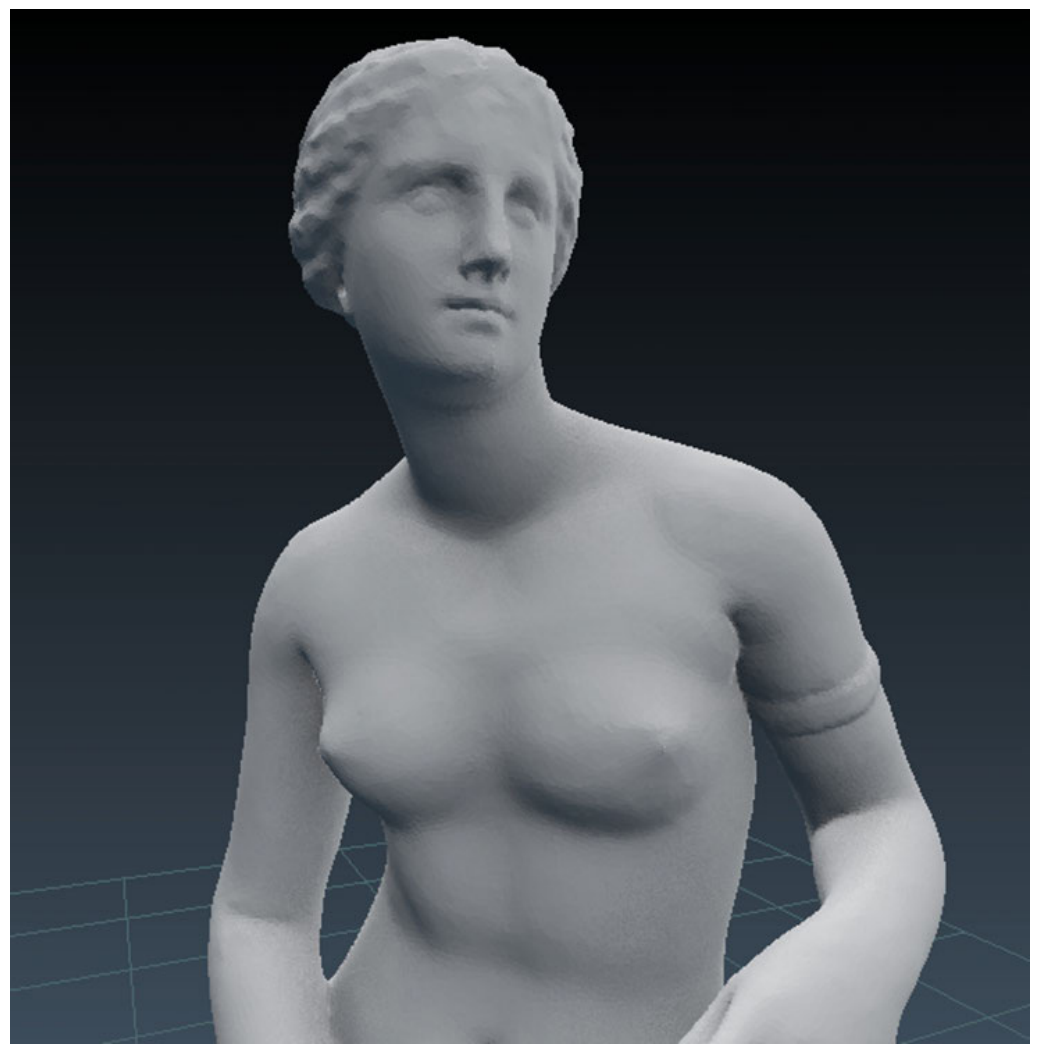

Figure 2. Statue of Venus

\section{THE CIRCUS OF MAXENTIUS}

The Emperor Maxentius commissioned two major building programs during his brief reign: the first in the center of Rome, along the Via Sacra, and the second just south of the city, along the Via Appia. Since he did not have official endorsement, Maxentius used these works to take advantage of his close connection with the traditional capital of the empire and to align himself with earlier emperors in order to demonstrate the legitimacy of his reign (306-312 AD) [Pisani Sartorio 1999]. It is revealing to focus on Maxentius' decision to construct a personal complex with a residential villa, a circus, and a mausoleum on the Via Appia, three kilometers outside of the city walls. Maxentius' desire to compete with the Tetrarchs and their personal palaces must have impelled him to chose an extramural location so that he could design his own palace free of the spatial and ritual constraints imposed by the older imperial residences on the Palatine Hill.

The three Maxentian monuments were strongly interconnected not only in sharing the same building technique of opus vittatum, but also physically. To integrate the three elements of the complex, passageways connected the precinct of the mausoleum to both the residence on the hill above and to the circus that lay in the valley to its east. A long, covered corridor stretched diagonally across the terraced slope to connect the imperial box on the north wall of the circus to the center of the Maxentian palace. Two main factors influenced the composition of the complex: the topography 
of the area, which determined the location and orientation of the circus, and the pre-existing architectural features.

The circus, built in 310-311 AD, is the site's best known feature and is one of the best preserved examples of a Roman hippodrome. The structure is oriented east-west within a natural valley between the hill of the late republican tomb of Caecilia Metella and the hill where the Maxentian villa is sited. The circus spans a length of 520 meters, and at its widest, it measures 92 meters across. The long sides of the track are not parallel, in order to leave the racing chariots just enough space while placing the spectators as close as possible [Ioppolo 1999]. The track is 36.90 meters wide on one leg and 29.60 meters on the other; the radius of curvature of the staircases flanking the triumphal gate is about 30 meters [Ioppolo 1999].

From an architectural point of view, the circus is essentially the dirt track and the central spine, a 296-meter-long narrow masonry construction. This structure includes at its ends the masonry foundations of the metae, with three marble cones above, the obelisk, and the ten basins of water of the euripus. The obelisk is now situated on the top of the Fountain of the Four Rivers designed by Bernini and located in Piazza Navona. The track was surrounded by steps, or stands, on which the spectators sat to watch the race; the steps are interrupted by the judges' tribunal situated on the southern side. On the northern side is the pulvinar imperatoris, connected to the villa by a passageway. It was possible to enter the circus through three gates: the Porta Pompae, the Porta Triumphalis and the Porta Libitinensis. The last was used as exit for horses and riders injured during the race [Ioppolo 1999]. Because of the presence of vegetation, it is not possible to discern the entire shape of the circus. The majority of the functional components are still visible, however, despite their ruinous condition, so it was possible to make some hypotheses and to proceed with the 3D modeling.

\section{3D MODELING}

\subsection{The towers}

The two towers of the oppidum were modeled one at a time because of the differences between the two objects. Archaeological plans and historical illustrations of this part of the circus were chosen as references; thanks to the archaeological data it was possible to create a metrically correct model of the plan. Once this part of the tower was finished, the object was extruded to produce the elevation, taking into account the archaeological remains, the reconstruction proposed in the historical illustrations, and the studies conducted on the masonry.

The northern tower is proposed as a three story building. The ground floor, covered by a vault, has two gates; the first is the entrance door, the second leads to the carceres, while the second floor has no door but two windows. According to the available data, the model proposes a stairwell on the northern side of the tower [Ioppolo 1999]. The southern tower is, as the northern one, a three story building, in which every level is covered by a vault. This tower has an entrance at the ground floor and a second one from the terrace on the first floor. Because of the absence of archaeological remains of stairs or steps, the model of the southern tower is proposed without a stairwell. In both cases, the reconstruction shows a terraced roof, even if no archaeological remains can confirm this hypothesis (Fig. 3). 


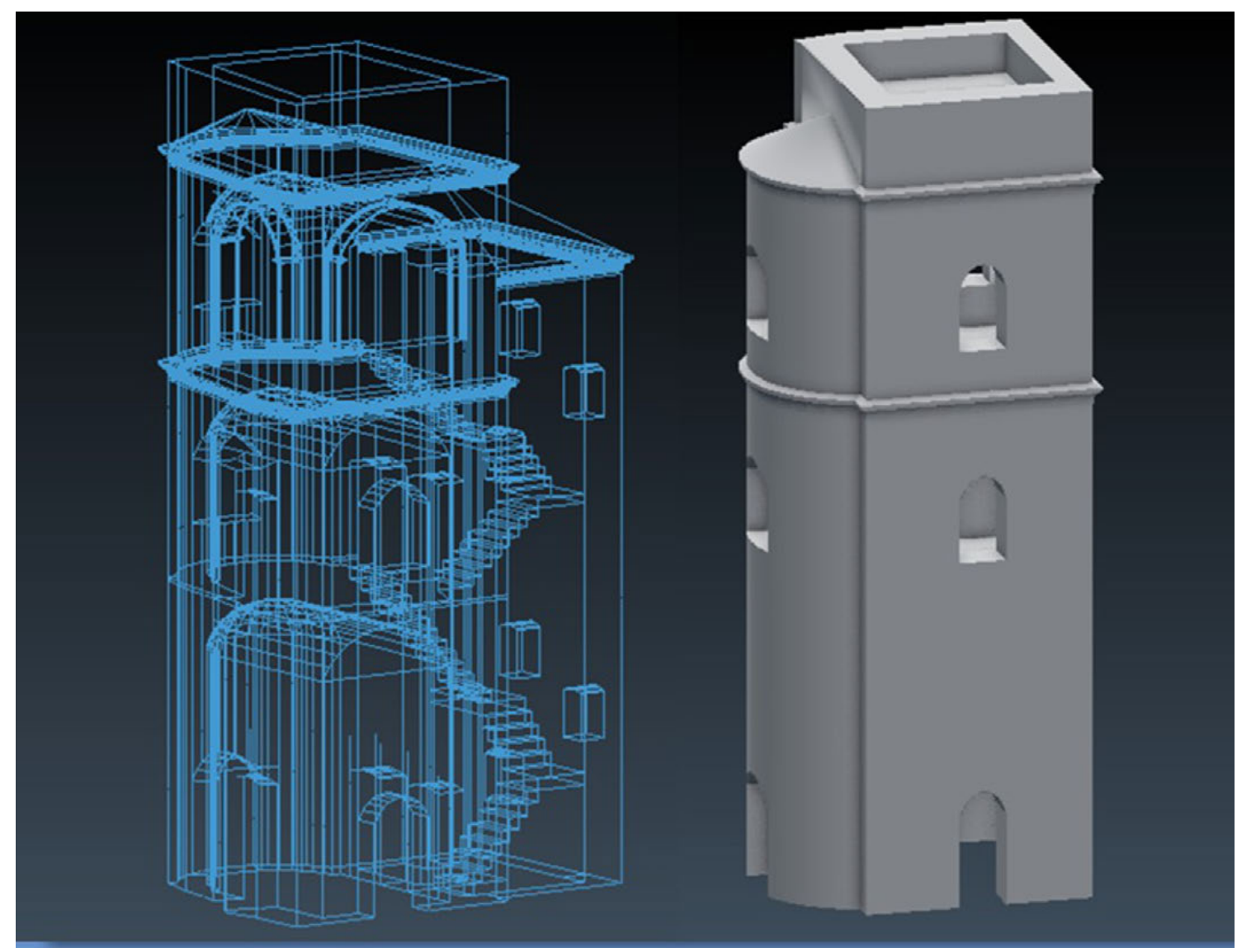

Figure 3. The towers (northern tower on the left; southern tower on the right)

\subsection{The carceres}

The archaeological remains of the carceres are too scanty to make a detailed hypothesis of restoration. The presence of some remains allows us only to recognize ten pillars that could have supported a series of arches and cross vaults. The resulting spaces were used to hold the chariots before the start of the race. The widest arch, in the middle of the structure, is hypothesized to be the Porta Pompae. In proposing this hypothesis, it was necessary to integrate archaeological data with some illustrations from the eighteenth century and to make comparisons with the hippodrome in Leptis Magna [Ioppolo 1999]. The choice to cover the structure with a series of vaults was made for statical reasons (Fig. 4). 


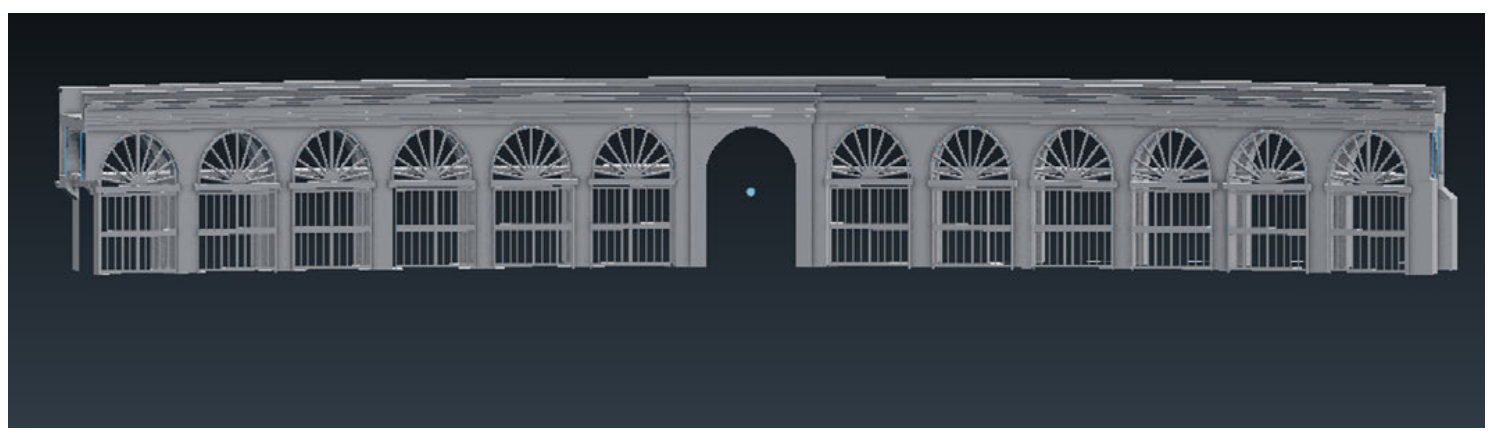

Figure 4. Carceres

\subsection{The stands}

The external perimeter of the circus is delineated by a long wall supporting the stands from which the spectators could watch the race. This architectural element is largely damaged but it is possible to understand its organization, thanks to studies conducted on a portion on the southern side where the state of preservation allows us to recognize all the features. The stands consist of a series of twelve steps divided into two levels by a wall in opus latericium. Each step is $39 \mathrm{~cm}$ high and $30 \mathrm{~cm}$ deep, so the stands could host around 10,000 spectators [Ioppolo 1999]. Access to the stands was provided by twin staircases flanking the doors located along the inner wall. Taking into account the measurements of the steps and the width of the surviving walls it is possible to estimate the total height of the stands at around 8 meters. In the upper part of the external wall, amphoras were embedded in the masonry core in order to lighten the structure. Even though the stands are in extremely poor condition and largely covered by vegetation, the remaining visible parts provided enough detail to model this important part of the circus. Starting from the archaeological plans and the axonometric drawings created by Ioppolo, it was possible to produce an accurate 3D model that includes the twin staircases and the embedded amphoras as well (Fig. 5).

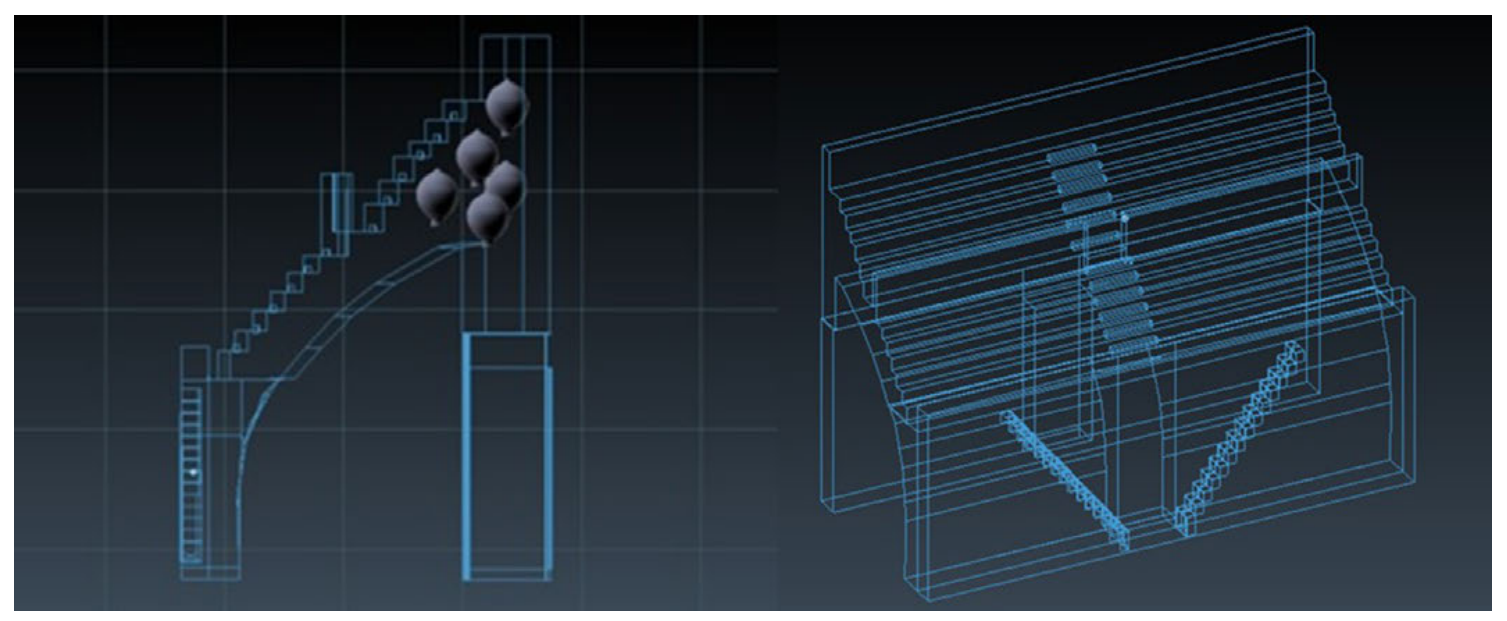

Figure 5. The stands 


\subsection{The tribunal}

The tribunal was modeled using as references the available archaeological plan and historical illustrations. In this case, there were many open questions about the hypothesis of restoration. The first was the presence of stairs by which to approach the terrace of the tribunal. This architectonic element is not well known, but in the model it is proposed as stairs that connect directly to the ground floor. The tribunal in its central part; the staircase is covered by a barrel vault. Other unknown elements are the three doors located at the level of the exedra. The one on the left leads to a small wedge-shaped room interpreted as closet between the octagonal structure and the portico. The central door has been interpreted as passageway that connects the exedra and the quadrangular room. The third one was probably a window used to give symmetry at the façade of the tribunal (Fig. 6). The last unknown part is the roof; there are no extant elements or useful comparisons enabling us to propose an accurate hypothesis, but we decided to show a roof composed of four distinct elements that cover the four different rooms.

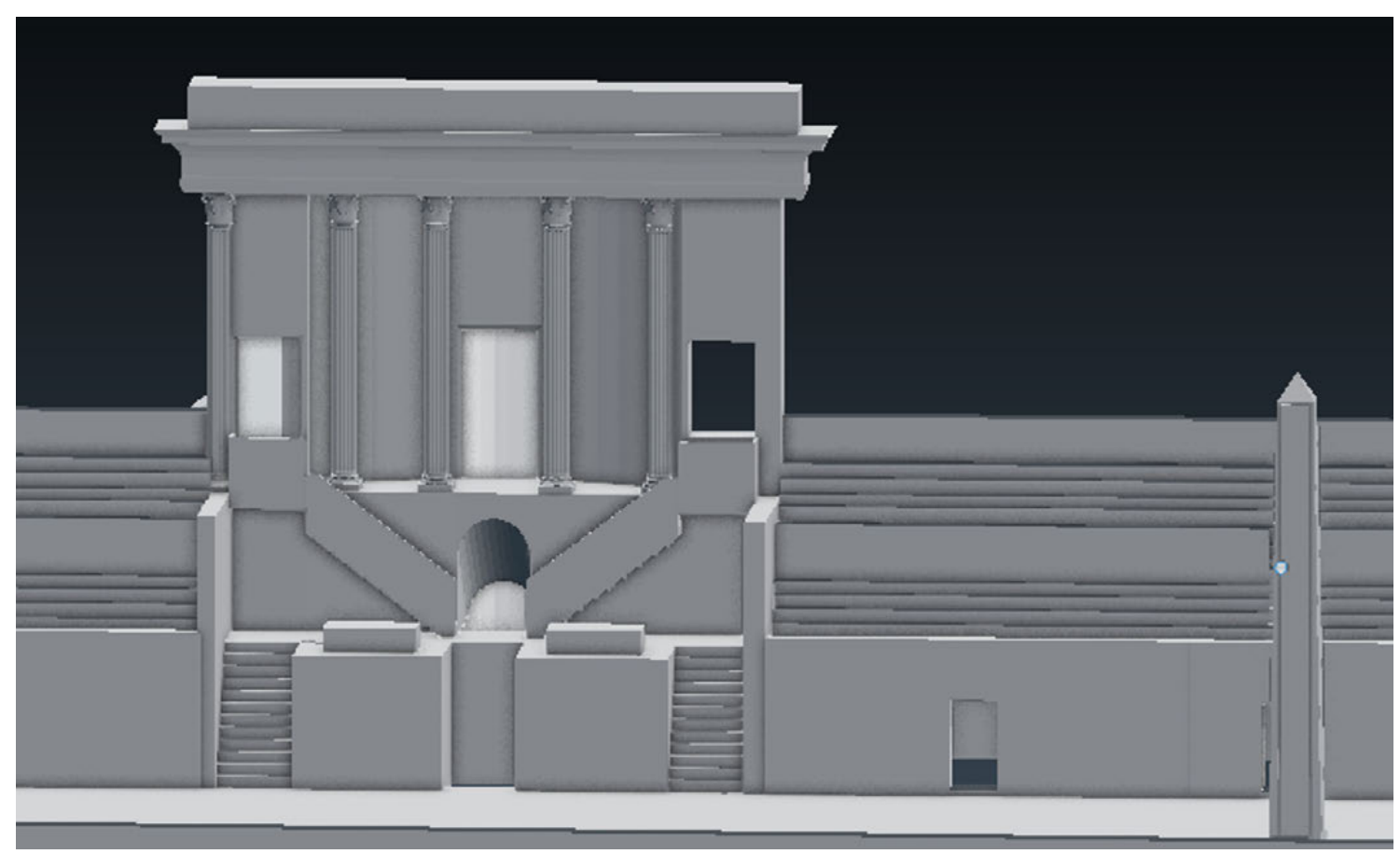

Figure 6. The tribunal.

\subsection{The pulvinar}

Along the northern side of the circus, close to the second meta, is situated the pulvinar, where the emperor used to watch the race. This feature was directly connected with the palace by means of a passageway. Unfortunately, the archaeological remains are too badly damaged to allow us to make a detailed hypothesis of their reconstruction. Moreover, this part of the circus was largely modified during the Middle Ages, and as a result it is not easy to recognize the Maxentian walls [Ioppolo 1999]. 
For this reason, the 3D model here presented is largely hypothetical and is based on the historical illustrations from the sixteenth century that show the state of preservation in that period.

The resulting model, according to the reconstruction proposed by Bianconi Fea [Ioppolo 1999], presents a rectangular room covered by a terrace and preceded by the stands, with columns on the façade (Fig. 7).

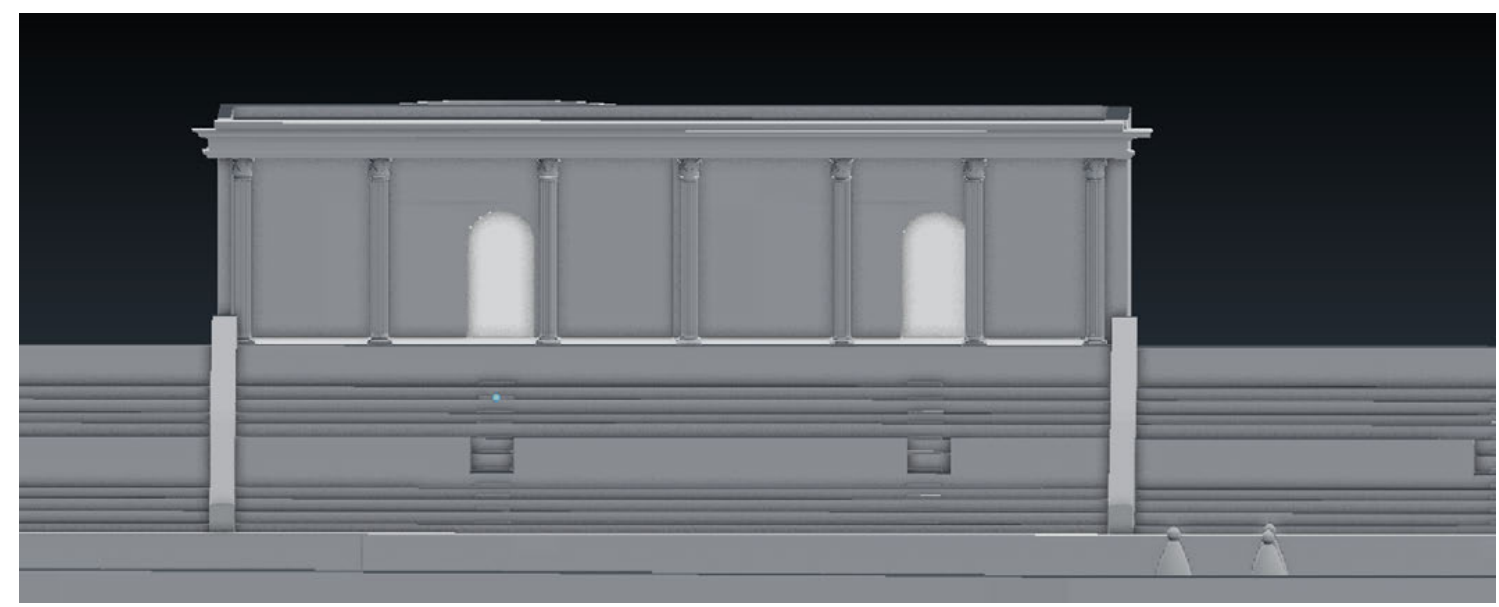

Figure 7. The pulvinar.

\subsection{The spina}

The spina was modeled using the archaeological plan and the data collected during the survey. This element is one of the best preserved and most recognizable, so it was also possible to integrate the archaeological data with mosaics and scenes represented on reliefs from the Roman period.

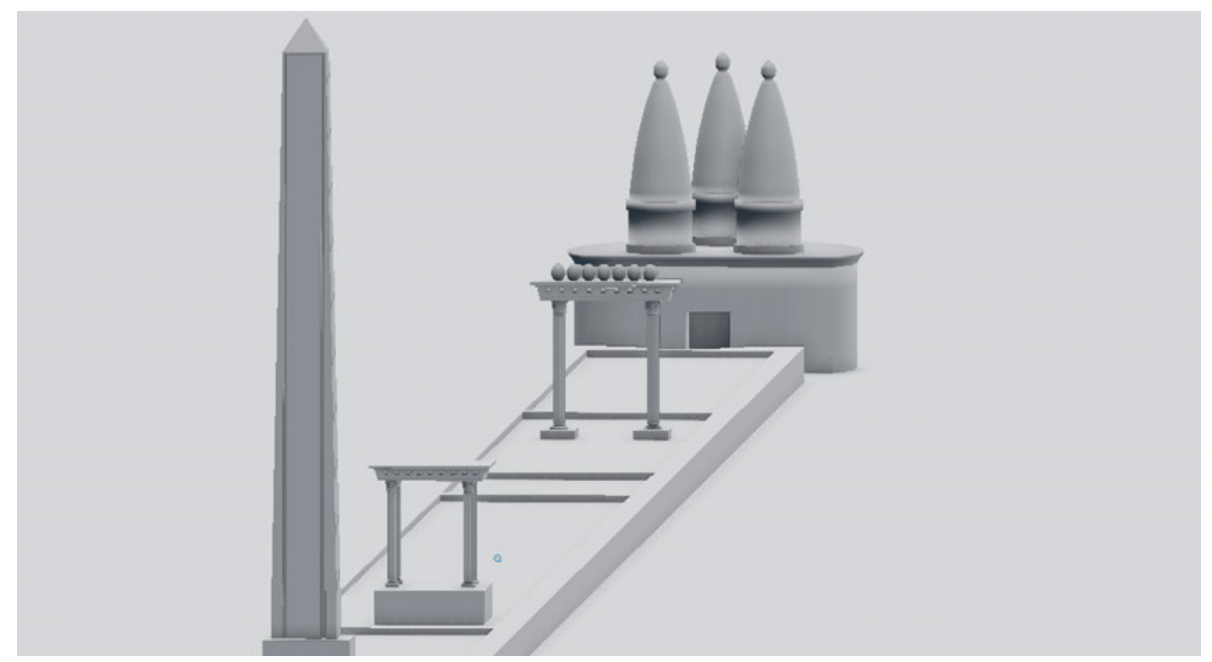

Figure 8. Arrangement of the spina. 
The result is a feature composed of two metae and a central canal, the euripus, inclosed by walls 1,20 meters in height. The euripus was decorated with statues, a mechanism to count the laps of the races, and an obelisk. All these elements were modeled and positioned. The obelisk and the lap-counting device were modeled using Blender, but to realize the statues the software ZBrush was chosen, in order to obtain a good and detailed result (Fig. 8).

\subsection{Porta Libitinensis}

The Porta Libitinensis is situated along the stands, close to the second meta. This gate, used as an exit for removing injured or dead horses and riders, consists of two arches connected by a vault. It is 4.44 meters wide and 6.89 meters long [Ioppolo 1999]. The Porta Libitinensis is still visible so it was quite simple to propose a 3D model by integrating the archaeological plan with new photos and direct studies (Fig. 9).

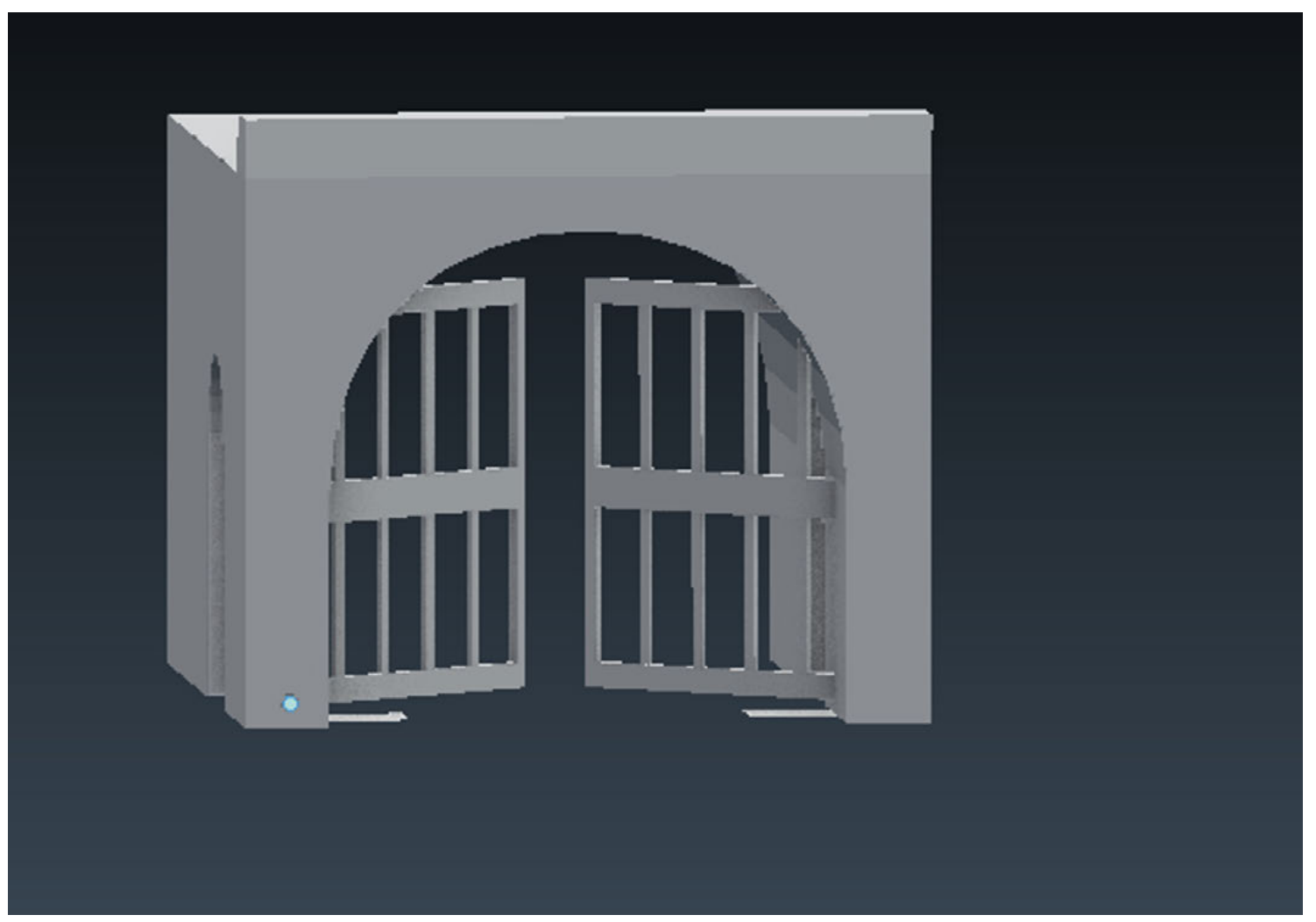

Figure 9. Porta Libitinensis

\subsection{Porta Triumphalis}

The Porta Triumphalis is located in the middle of the eastern side and consists of two walls surmounted by a barrel vault and an attic. The structure still exists, so we could proceed with our model with confidence in the details. Today the visible remains include the walls, the vault, the two 
stairs connecting the ground floor with the stands, and the steps leveling the slope between the track and the external ground. The only missing part is the attic but, thanks to comparison with contemporary arches, it was possible to hypnotize its likely appearance (Fig. 10).

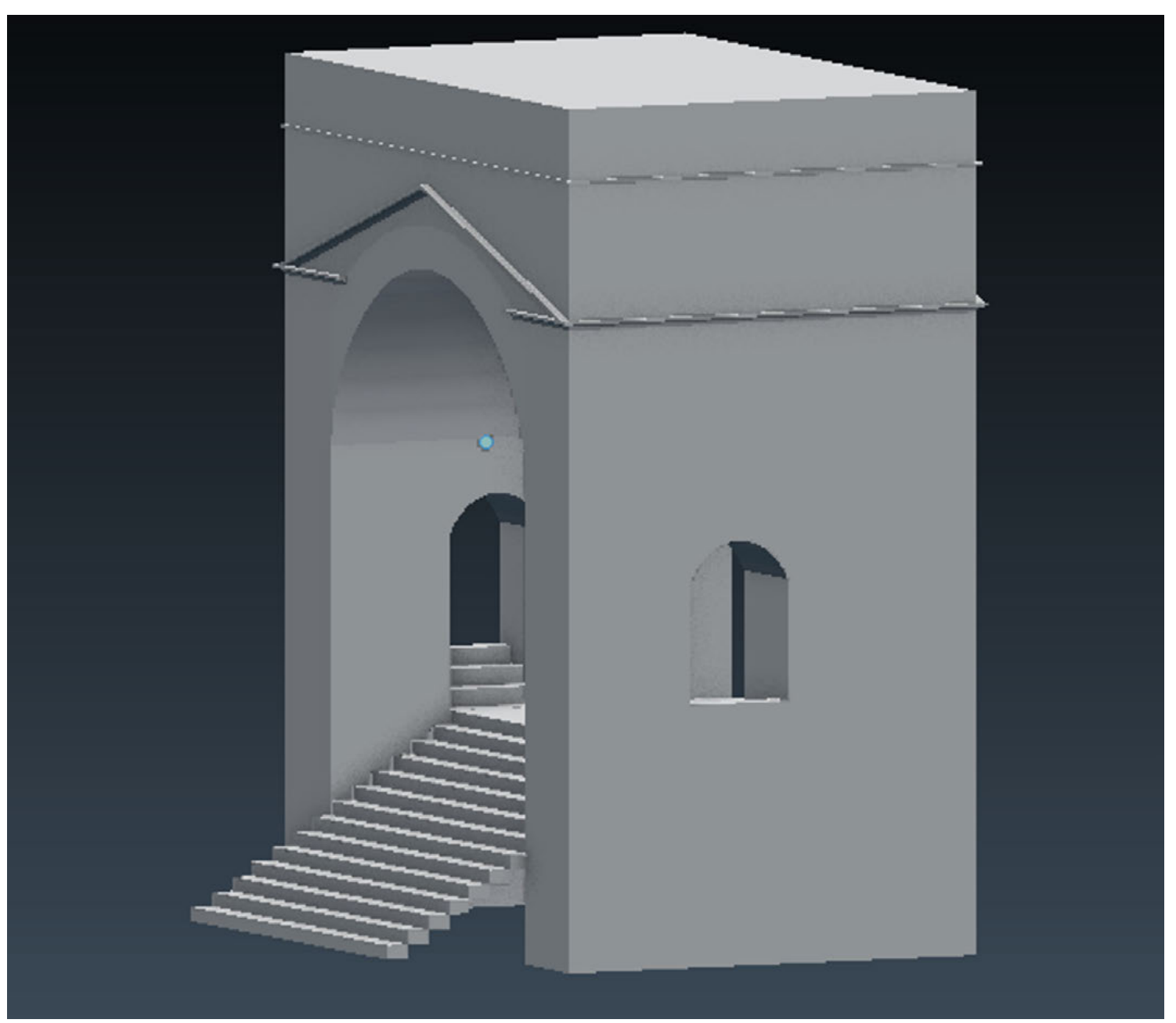

Figure 10. Porta Triumphalis.

\subsection{The terrain}

To complete the model of the circus it was necessary to elaborate a 3D model of the landscape in which the monument stood. Starting from altimetry data provided by IGM (Istituto Geografico Militare) cartography, it was possible to produce a metrically correct model of the terrain. After having imported into Blender the contour lines, previously extracted from the maps, it was first necessary to convert the curves into a mesh. Then, using the add-on Delaunay triangulation and Voronoi diagram, it was possible to generate a 3D model. To make the object more manageable, the Shrinkwrap modifier was applied. This modifier works by putting on the mode a lan that 
automatically covers the geometry while keeping the shapes and measurements. The result is an accurate, detailed and topologically correct model of the terrain (Fig. 11).

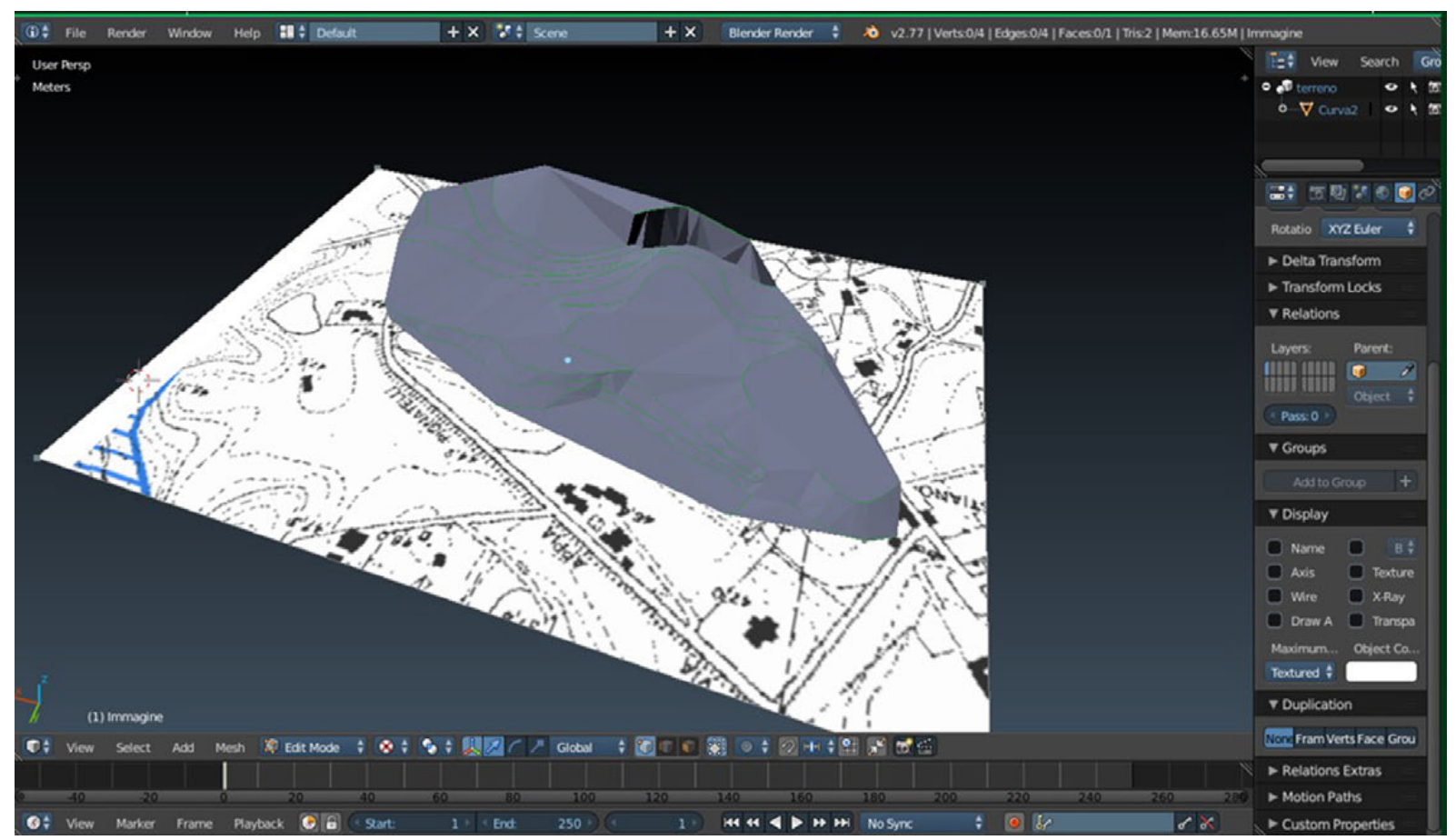

Figure 11. 3D model of the terrain.

\section{TEXTURING}

Last step of the project was texturing the 3D model. Because of the poor state of preservation, detailed data were not available but, thanks to previous studies, it was possible to make some hypotheses of restoration. In considering the spina, pulvinar, tribunal and Porta Triumphalis, we propose a marble facing. This hypothesis seems to be confirmed by comparisons with others monuments and by the finding of marble fragments. The situation of the carceres is more complicated; due to the lack of significant remains it is impossible to know for certain if there was a facing or not. Nibby asserted that this feature was covered by marble, basing his hypothesis on the quantity of marble found close to the pillars [Luschi 1999]. It is also possible that the only part covered by marble was the central arch, the so-called Porta Pompae. Thus we propose two solutions: the first presents a complete marble covering (Fig. 12) and the second shows the masonry exposed and only the Porta Pompae with a marble facing (Fig. 13). 


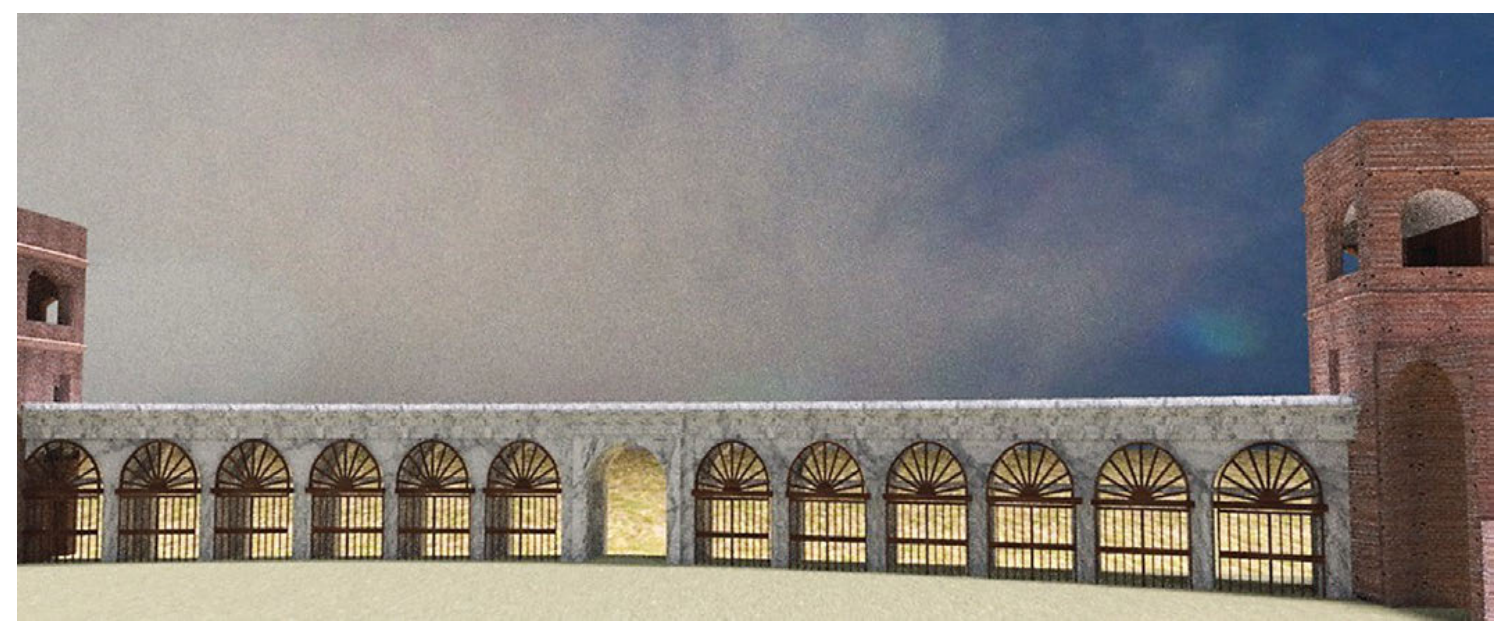

Figure 12. Carceres completely covered.

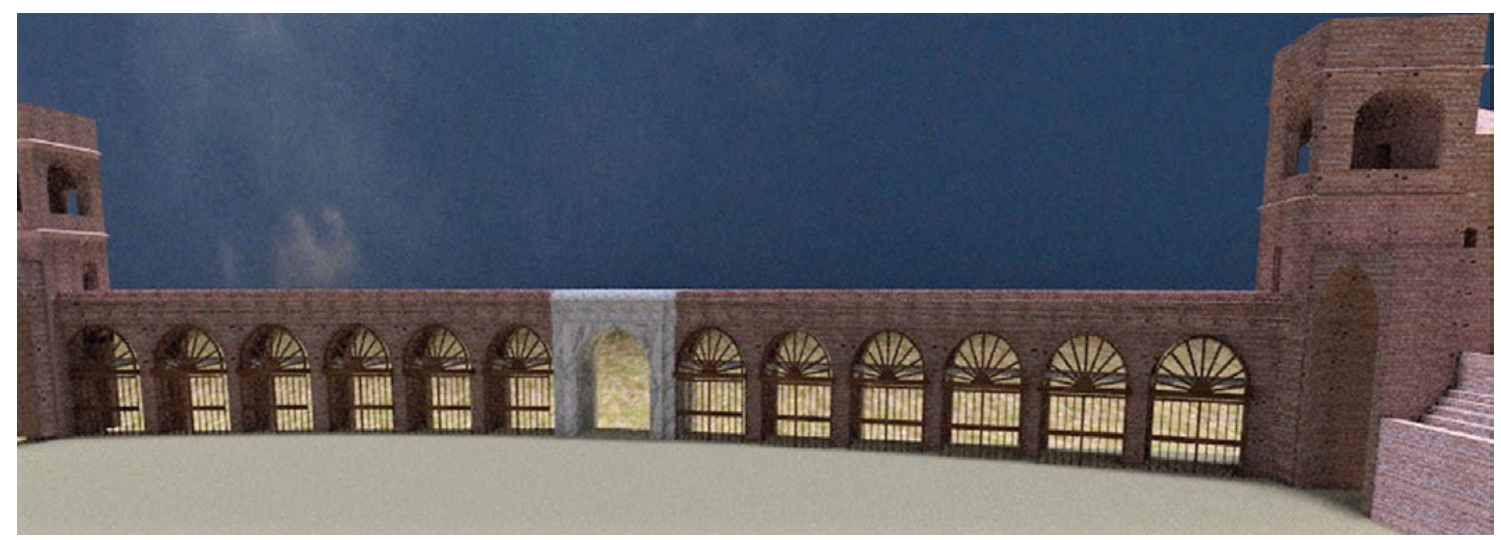

Figure 13. Carceres with masonry exposed.

To obtain a photorealistic result, the model was textured in Blender using the Node Editor in Cycles Render. This tool allows us to produce a detailed texture easily and quickly, through the use of nodes reproducing the physical effects related to the behavior of light. The same editor was used to realize the water of the euripus (Fig. 14) and to texture the terrain. 


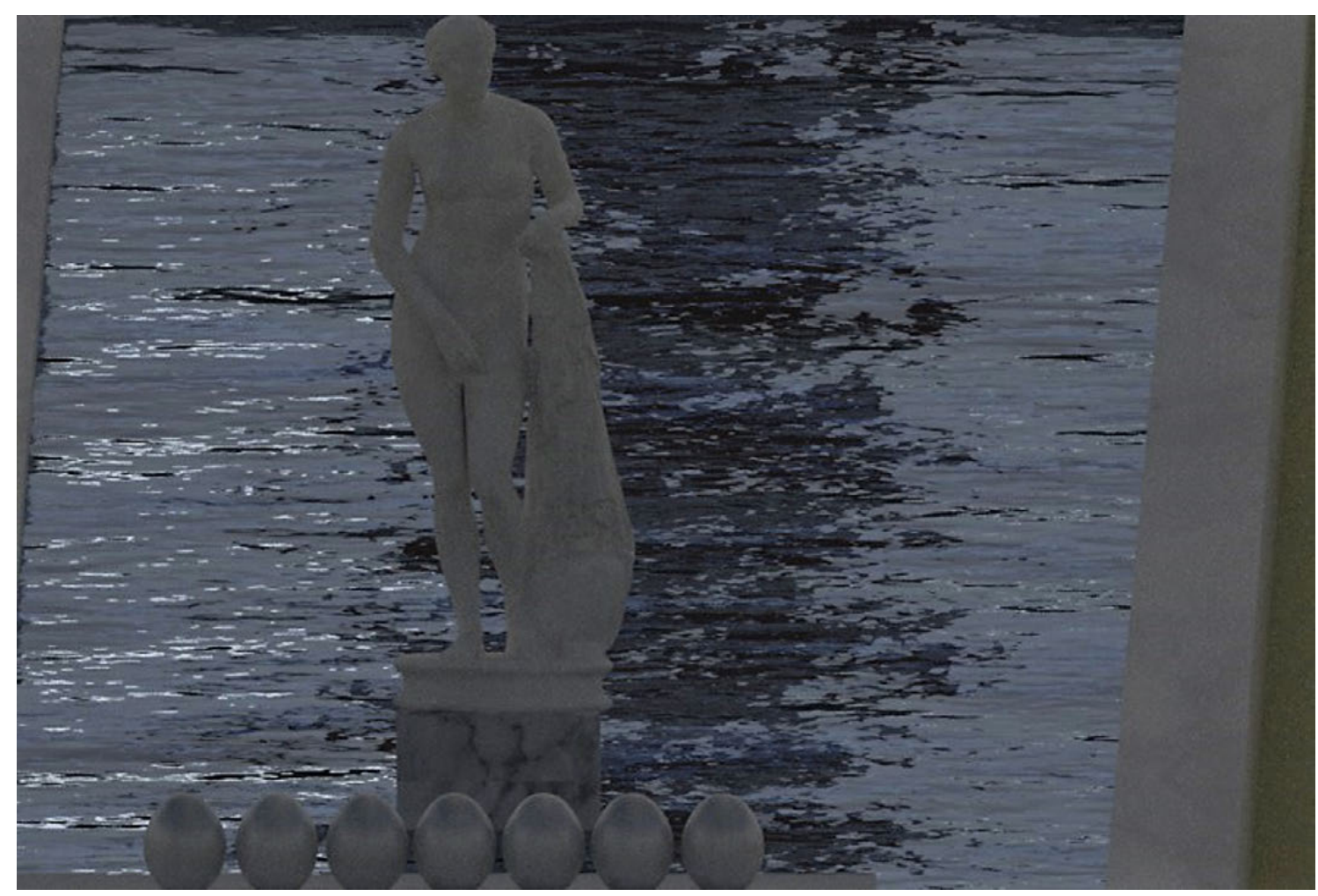

Figure 14. Euripus and statue of Venus.

\section{CONCLUSION}

The result of this project is a metrically correct 3D model of the Circus of Maxentius useful in two ways. On the one hand, the model could stimulate wider reflections on other archaeological topics, such as structural aspects and decoration systems for this type of Roman monument. On the other hand, this model presents a full reconstruction of the monument to a contemporary public audience.

The production of a 3D model is a good opportunity to deepen the knowledge of the monument and to verify the hypotheses of restoration. Moreover, the study of an accurate 3D allows us to pose new questions concerning the Circus of Maxentius and the entire complex. The same methodology could be applied to many projects, in order to propose new hypotheses and to improve the knowledge of the monuments under investigation.

3D models also represent a good dissemination tool. For example, our model could be used to show to the public how the monument looked during the fourth century AD. In this regard, details of the model parts have been included in an augmented app in order to provide a simple and involving way to enjoy the monument (Fig. 15). 


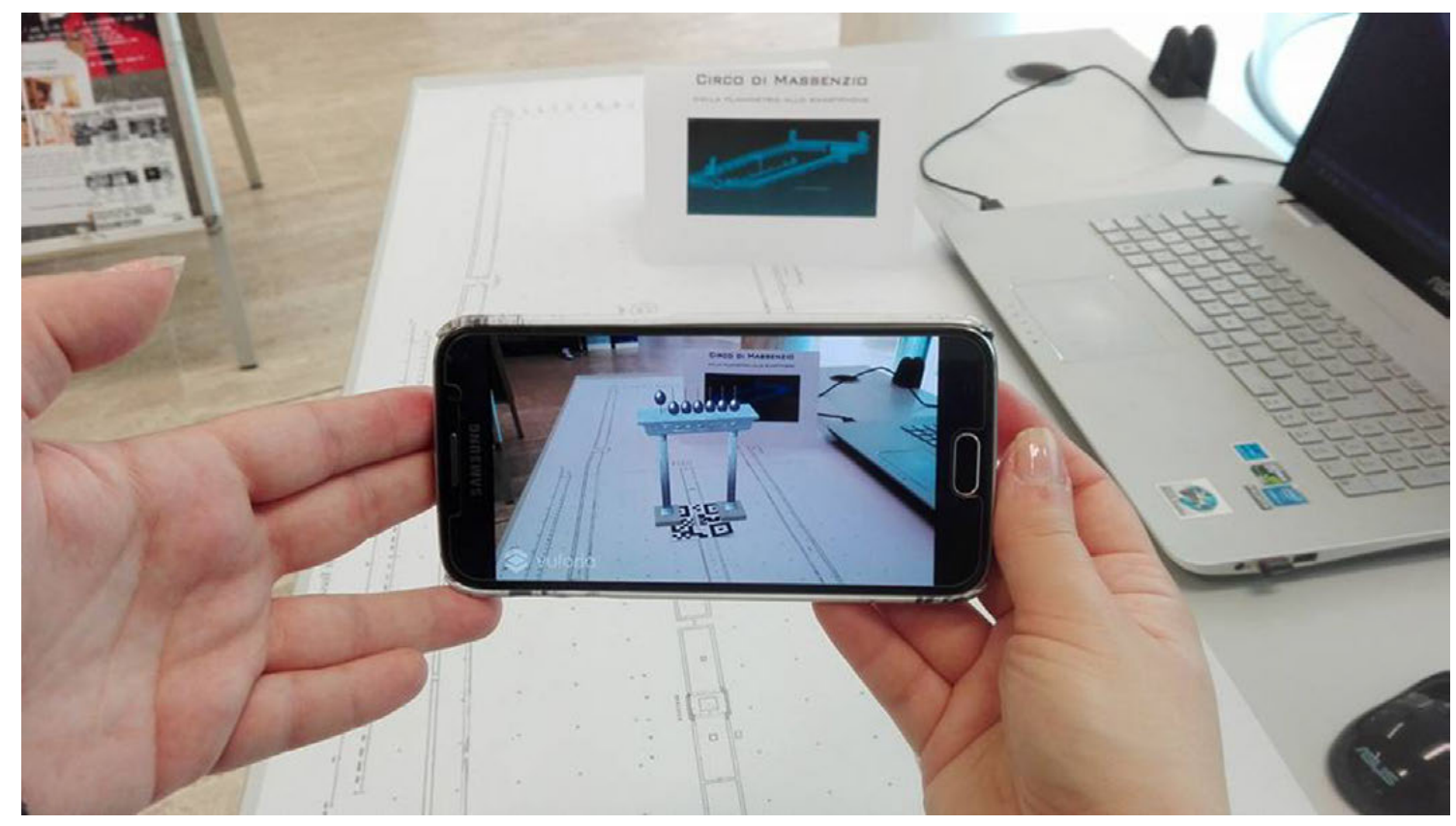

Figure 15. Augmented reality app.

\section{ACKNOWLEDGEMENTS}

We gratefully acknowledge Dr. Ersila Maria Loreti (Sovrintendenza Capitolina ai beni Culturali) for supporting the research. We also give special thanks to Michele Camicioli for his precious work on the statue's model and to Francesco Iaia for creating the augmented reality app.

\section{REFERENCES}

Giuseppe Ioppolo. 1999. La struttura architettonica. In La villa di Massenzio sulla Via Appia. Il circo. Istituto Nazionale di Studi Romani, Roma, 103-195.

Licia Luschi. 1999. Gli scavi di Nibby e la decorazione dell'euripus. In La villa di Massenzio sulla Via Appia. Il circo. Istituto Nazionale di Studi Romani, Roma, 197-217.

Giuseppina Pisani Sartorio. 1999. Inquadramento storico. In La villa di Massenzio sulla Via Appia. Il circo. Istituto Nazionale di Studi Romani, Roma, 89-100.

Received March 2017; revised July 2017; accepted August 2017. 